\title{
Contractual and Relational Governance, ICT Skills and Organization Adaptations, and Cloud Computing Benefits
}

\author{
Euripidis Loukis \\ University of the Aegean \\ eloukis@aegean.gr
}

\author{
Niki Kyriakou \\ University of the Aegean \\ nkyr@aegean.gr
}

\begin{abstract}
Cloud Computing (CC) has high potential to offer to firms important benefits, concerning both costs reduction, and in general efficiency improvements, as well as innovation facilitation and support. However, these benefits are not straightforward and automatically generated; their realization as well as their magnitude will depend on a variety of factors. Nevertheless, limited empirical research has been conducted in order to identify $C C$ benefits' determinants. This paper contributes to filling this research gap. It empirically investigates the effects of a) the contractual and relational governance of firm's relationships with its CC services providers, and $b$ ) the adaptations of the skills of firm's ICT personnel, as well as its internal ICT organization, to this new CC paradigm, on the magnitude of CC benefits. Our study uses data collected through a questionnaire from 115 Greek firms using CC services. It has been concluded that all the above four examined factors impact positively the benefits firms obtain from $C C$; the effect of the adaptation of the skills of firm's ICT personnel is the strongest, followed by the effect of the relational governance.
\end{abstract}

\section{Introduction}

Cloud Computing (CC), if properly exploited and managed, has a high potential to offer significant benefits to firms, which concern both reduction of the ICT and in general the operating costs of the firm, leading to efficiency gains, as well as facilitation and support of innovation activity [2, 12, 24, 29, 31, 32]. However, these benefits are not straightforward and automatically generated. There has been some previous qualitative research [27, 28, 33, 34] concluding that in order to exploit the full business value potential of CC and gain significant benefits from it, it is necessary to make some changes/adaptations of the skills of firm's ICT personnel to this new CC paradigm of sourcing ICT services, and also of its internal organization of ICT exploitation (e.g. decentralization of ICT related decision making from the ICT unit towards the business units). Also, previous literature on ICT outsourcing has concluded that its outcomes and benefits are shaped by a variety of factors, which concern the contractual and relational governance of firm's relationships with its external ICT services providers, the characteristics and capabilities of the provider and the client firm, etc. (see literature reviews in $[16,17]$ ); since the use of CC services by firms is a specific form of ICT outsourcing these factors might influence the benefits generated by $\mathrm{CC}$ as well.

Nevertheless, limited empirical research has been conducted concerning the 'real' benefits obtained by firms from the use of $\mathrm{CC}$, as well the factors affecting them (see section 2.1). Though there is extensive empirical research on the factors affecting the adoption of CC (e.g. see [19]), quite limited is the empirical research that has been conducted on the factors affecting the benefits from CC. This research is quite necessary, because $\mathrm{CC}$ is a new paradigm of sourcing the ICT services required by firms for supporting their processes and activities, based on external providers, which is quite different from the previous 'on-premises' paradigm, based on internal ICT services provision. So, firms still do not know how to exploit this new CC paradigm, and what actions they have to take, in order to gain more benefits from it. Therefore, it is of critical importance to conduct research in order to identify and understand the factors and preconditions that affect the level of benefits that CC generates, and develop a knowledge base concerning the maximization of $\mathrm{CC}$ business value.

This study contributes to filling the existing research gap concerning CC benefits' determinants. In particular, it empirically investigates the effects of:

a) the degree of the contractual and relational governance of firm's relationships with its $\mathrm{CC}$ services providers,

b) as well as the degree of the adaptation of the skills of firm's ICT personnel, as well as of its internal ICT organization, to this new CC paradigm, on the magnitude of the benefits generated by $\mathrm{CC}$. Building on previous research, on one hand in the area of ICT outsourcing (concerning the determinants of its outcomes and benefits), and on the other hand 
in the area of $\mathrm{CC}$ (concerning the firm level adaptations it necessitates in ICT skills and organization), we formulate four relevant research hypotheses (see section 3). These research hypotheses are tested based on data collected through a questionnaire from 116 Greek firms using CC services.

This paper consists of six sections. In section 2 the background of our study is presented. Then in section 3 research hypotheses are formulated. In section 4 the data and the method of this study are described. The results are presented in section 5 and discussed in section 6 . In the final section 7 the conclusions are summarized and future research directions are proposed.

\section{Background}

\subsection{Cloud Computing Benefits}

The wide range of benefits that $\mathrm{CC}$ can offer to firms has been extensively described in previous literature $[2,4,12,13,15,22,24,31,32]$. These benefits include reduction of the cost and improvement of the quality of the ICT support of firm's processes and activities, conversion of ICT capital investments to operating costs, ubiquitous access to ICT infra-structure using various kinds of devices (e.g. desktop and laptop computers, mobile smartphones); and also, rapid and low cost development of ICT support required for process, product and service innovations, improvement of firm's organizational agility, provision of flexible cost-effective computing capacity for supporting firm's growth, and rapid and low cost access to new technologies (e.g. business analytics, mobile services) and high level ICT-related skills.

However, limited empirical research has been conducted concerning the 'real' benefits firms obtain from $\mathrm{CC}$ and their determinants, in order to investigate to what extent the above potential CC benefits are realized, and which factors determine their magnitudes. In [29] are investigated the effects of CC use by firms on their economic as well as environmental performance, using survey data collected from 247 ICT and supply chain professionnals. It is concluded that the use of $\mathrm{CC}$ has positive impact on both performances, and also that the impact on economic performance is partially mediated by the supply chain collaboration enabled by CC. [21] investigates the role of SaaS in firms' ICT-enabled innovation, using data collected through a survey from 243 USA firms. It concludes that the use of SaaS has a positive impact on ICT-enabled innovation, which increases if there is previous ICT outsourcing experience, flexibility of firm's ICT infrastructure and process management maturity. In [7] are examined the relations of firm's ICT technical, managerial and relational capabilities with $\mathrm{CC}$ success and finally with firm performance, using data collected from 302 Korean firms. They conclude that all these three capabilities affect positively the degree of CC success; the effect of the ICT relational capabilities, is the strongest, followed by the effects of the ICT technical capabilities, and then the ICT managerial capabilities.

In conclusion, limited empirical research has been conducted concerning the determinants of CC benefits, which has examined the effects of only a small number of factors on CC benefits. Hence, there is limited understanding of the factors and preconditions that determine the magnitude of $\mathrm{CC}$ benefits. Our study contributes to filling this research gap, by empirically investigating the effects on $\mathrm{CC}$ benefits of four factors, which have not been investigated in previous relevant empirical literature: the degree of contractual and relational governance of the relationships with $\mathrm{CC}$ service providers, and also the degree of adaptation of firm's ICT personnel and internal ICT organization, to this new CC paradigm.

\subsection{Contractual and Relational Governance}

Firms have various types of relationships with other firms, and as part of them they conduct significant exchanges of products, services and financial resources. There are two main mechanisms of governance of these inter-organizational relationships: the 'contractual governance' and the 'relational governance' [8, 10, 11, 18, 23, 26].

The contractual governance $[3,8,18,26]$ is based on comprehensive formal written contracts. Contracts include the detailed products and services that have to be provided by the supplier, their quality levels and the ways/procedures of their measurement, as well as the prices to be paid for them by the client; also, they include specific sanctions/penalties for the case that the required quantity/quality levels are not achieved, or there are delays in deliveries. Furthermore, contracts usually define detailed descriptions of forms of communication between client and supplier, and procedures for handling problems and contingencies that might appear, as well as for resolution of disputes. Sometimes there are also clauses describing procedures and terms for meeting additional needs of the client in the future, as well as for addressing changes of the initial needs (e.g. needs for higher volumes of products and services, or for new ones, new technologies, etc.). 
On the contrary, the relational governance is based on the development of informal unwritten norms, attitudes and social processes between the supplier and the client, which promote information exchange, trust, collaborative problem solving, flexibility, mutual adaptation, and aim at better and smoother cooperation, higher level of satisfaction for both parties, and finally long term business relationship $[6,8,18,26]$. In particular, the most important element of relational governance is the extensive bi-directional information exchange between the client and the supplier: on one hand the client provides extensive information to the supplier concerning their needs, activities, internal business processes, problems, strategic goals, etc.; on the other hand the supplier provides extensive information to the client concerning the whole range of their products and services, their technological capabilities, ways of better exploitation of them by the client, etc. Another important element of relational governance is the establishment of a positive attitude in both parties for solving problems and resolving disputes in close co-operation, and abstaining from opportunism, aiming to achieve mutual benefit and satisfaction; and also a positive attitude and flexibility in both parties for responding positively to requests for changes required by the other party.

Previous research in the area of ICT outsourcing has shown that both contractual and relational governance of firm's relationships with its external ICT services providers are important, and influence positively the outcomes and resulting benefits $[8,11$, $16,17,18,25]$. Taking into account that the use of $\mathrm{CC}$ services by firms is a specific form of ICT outsourcing, our study investigates to what extent the degree of contractual and relational governance of the relationships with $\mathrm{CC}$ services providers affect the magnitude of the benefits generated by $\mathrm{CC}$.

\subsection{Cloud Computing Adaptation}

The CC constitutes a quite different paradigm of sourcing the ICT services required for supporting firms' activities and processes, in comparison with the 'on-premises' paradigm. In the on-premises paradigm ICT services are produced mainly internally, based on assets (hardware and software) owned by the firm, installed in its premises, and administered and supported by its own ICT personnel. On the contrary, in the $\mathrm{CC}$ paradigm the ICT services are produced externally, at the CC providers' premises, using assets owned, administered and supported by them, and are delivered to the firm through the Internet. For the above reasons the $\mathrm{CC}$ paradigm requires different
ICT personnel skills and ICT organization in the adopting firm from the on-premises paradigm. In this direction, recent qualitative research (based on interviews) has revealed that $\mathrm{CC}$ benefits are not straight-forward and automatically generated, but depend on the extent of making some adaptations in the skills of firm's ICT personnel, as well as its internal ICT organization (e.g. ICT processes, roles, etc.) $[27,31,32]$; since the existing ICT skills and internal organization are currently aligned with the 'on-premises' paradigm, they have to be changed and adapted to the needs of the new CC paradigm, in order to exploit the full potential of it, and gain significant benefits.

In particular, the adoption of $\mathrm{CC}$ changes significantly the set of tasks that have to be performed within a firm in order to obtain the required ICT support of its activities and processes. This new tasks' set includes less technology related tasks (e.g. less IS development, administration and support), with more focus on integration between onpremises systems and various external CC services [27]. At the same time, it includes more business related tasks: extensive external information about existing relevant $\mathrm{CC}$ services offered by multiple providers should be analyzed mainly from a business perspective, with respect to their capability and suitability for supporting firm's business activities and processes, in order to identify the ones that can be used by the firm and offer significant business benefits [34]. Furthermore, for the selected CC services contracts should be negotiated with their providers, signed and then monitored and managed. This results in a reinforcement of the role of firm's business units in the $\mathrm{CC}$ paradigm, and at the same time a weakening of the role of the ICT unit.

At the same time, the adoption of $\mathrm{CC}$ necessitates a change of the role of firm's ICT unit, in order to be adapted to the needs of the $\mathrm{CC}$ paradigm: from ICT services provision (through the development of applications, software packages acquisition, systems administration and support, etc.), towards the central coordination and support of the selection and use in the firm of various external CC services, and also the interconnection - integration of them with firm's internal on-premises systems [31, 32]. At the same time part of ICT decision making should be decentralized to some extent from the ICT unit to the business units, increasing their involvement and the role in the $\mathrm{CC}$ related decisions. Furthermore, training should be provided to firm's ICT personnel about the technologies of $\mathrm{CC}$, the capabilities they provide, its interconnection/integration with onpremises IS, as well as the monitoring and management of contracts and business relationships 
with CC services providers. Additionally, in the CC paradigm the ICT personnel should become more business oriented, so it should receive also business training, in order to acquire more business knowledge concerning firm's business processes and strategic goals.

Finally, in order to have higher level of benefits from $\mathrm{CC}$ it is important to adopt not a fragmentary and un-coordinated approach to the use of CC services by the firm, but a more coordinated and strategic one: a CC strategy should be developed concerning the types of $\mathrm{CC}$ services that will be used, the applications they will be used for, the business objectives of $\mathrm{CC}$ use, and also the applications that will remain 'on-premises' [2, 15, 27]. Beyond the strategic level, at the operational level it is important to develop also new processes for $\mathrm{CC}$ exploitation [31, 32]: for the cooperation between the ICT unit and the business units concerning the use of $\mathrm{CC}$, for the cooperation with $\mathrm{CC}$ providers, for the quality control of the $\mathrm{CC}$ services, etc.

However, there is a lack of empirical research concerning the impact of the above adaptations of the skills of firm's ICT personnel, as well as its internal ICT organization, to the needs of the CC paradigm, on the magnitude of the benefits generated by $\mathrm{CC}$. Our study contributes to filling this research gap.

\section{Research Hypotheses}

Based on the above background we developed four research hypotheses, which concern the effects of the contractual and relational governance of firm's relationships with its $\mathrm{CC}$ service providers, as well as the adaptation to the CC paradigm of firm's ICT personnel skills and ICT organization, on the magnitude of the benefits generated by $\mathrm{CC}$. The research model of our study is shown below in Fig. 1 .

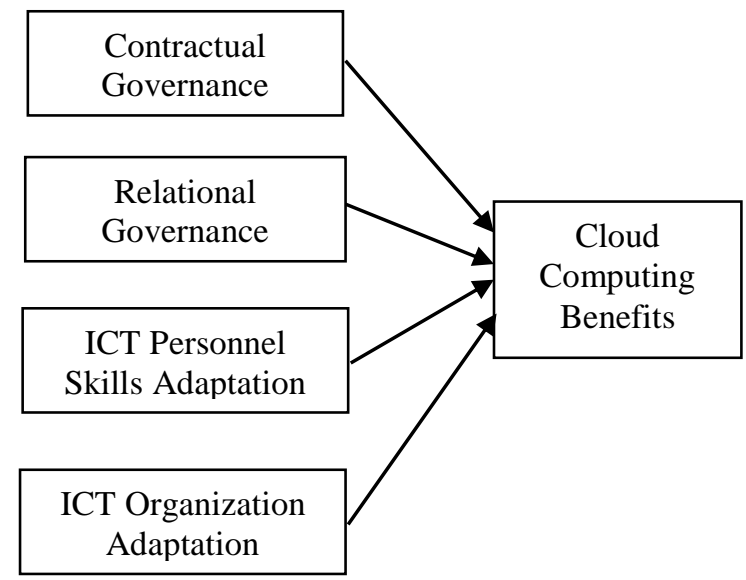

Figure 1. Research model
Our first research hypothesis concerns the effect of the degree of contractual governance of firm's relationships with its $\mathrm{CC}$ service providers on the benefits it obtains from $\mathrm{CC}$. Higher degree of contractual government means more comprehensive and complex contracts with the $\mathrm{CC}$ service providers, which clearly describe in detail the $\mathrm{CC}$ services to be provided, their quality levels, as well as the ways and procedures of measuring them, and specific sanctions/penalties if they are not achieved [3, 8, 26]. These are expected to lead to the provision of higher quality of CC services, and reduce opportunistic behaviors of CC service providers; this will result in higher quality of electronic support of firm's activities and business processes, provision of all agreed capabilities and functionalities, as well as levels of availability and security, etc. Furthermore, the description in the contracts of specific forms and ways of communication between the firm and its CC service providers, as well as procedures for handling problems and contingencies, and for resolution of disputes, will result in addressing quicker and more effectively any problems, contingencies and disputes that might appear, preventing possible reductions of service quality, cost overruns, or high 'transaction costs' [30] that might result from them.

Complex and comprehensive contracts include also clauses with detailed procedures for covering new additional needs of the client firm, beyond the ones mentioned in the contract, such as needs for higher volumes of services, for new services, for new technologies, etc. $[8,25,26]$. These enable the firm to access rapidly and with good terms the appropriate $\mathrm{CC}$ services required in order to respond to various changes/challenges in its external environment, enabling it to exploit better the CC for improving its 'organizational agility' [20]. Furthermore, such clauses concerning new needs oriented allow the firm to access rapidly and with good terms the appropriate $\mathrm{CC}$ services required for the electronic support and facilitation of method/process innovations, as well as products/services innovations.

For all the above reasons, we expect that higher degree of contractual governance of firm's relationships with CC its services providers (meant as more complex and comprehensive contracts with them) will lead to more benefits from CC. So, our first research hypothesis is:

H1: The degree of contractual governance has a positive effect on CC benefits.

Our second research hypothesis concerns the effect of the degree of relational governance of firm's relationships with its $\mathrm{CC}$ service providers on the benefits it obtains from CC. Higher degree of relational governance leads to more open and 
extensive exchange of information between the firm and its CC services providers, with higher trust and more constructive attitude from both sides, aiming at mutual benefit and satisfaction, as well as long term relationship [8, 18, 26]. This includes on one hand provision by the firm to its $\mathrm{CC}$ services providers of extensive information concerning its activities, internal business processes, problems, strategic goals and directions, as well as the resulting ICT support needs. On the other hand, it includes provision to the firm by its CC service providers of extensive information concerning the whole range of services they can provide, their technological capabilities, and the continuous improvements and enrichments of their services, as well as proposals for a better exploitation of them by the firm. The above enable a better and more rational selection by the firm of the most appropriate CC services, as well as customizations of them, and also their integration with firm's onpremises IS (based on extensive relevant technical information and knowledge transferred by the CC services providers), and in general a better use and exploitation of the full range of capabilities of these $\mathrm{CC}$ services. Furthermore, they enable the firm to exploit rapidly and at low cost new technologies (e.g. business analytics, big data, mobile technologies, etc.), by using relevant new $\mathrm{CC}$ services that providers continuously introduce [5, 14], without having to make additional investments. The above result in higher quality and lower cost electronic support of firm's activities and business processes, as well as better facilitation and support of innovation.

Furthermore, higher degree of relational governance creates a positive attitude in both parties for solving problems in close co-operation, resolving disputes, as well as responding positively to requests for changes required by the other party, aiming at mutual benefit and satisfaction, and abstaining from opportunistic behaviors $[8,18,26]$. This reduces the deteriorations in the quality of firm's electronic support, as well relevant costs' overruns, which are usually caused by such problems and disputes. At the same time, a positive attitude of the $\mathrm{CC}$ service providers towards firm's requests for changes in the provided services (e.g. for higher volumes of used $\mathrm{CC}$ services, or for new services, or new technologies), will enable the firm to make better use of CC for the support of innovations, as well as the enhancement of firm's agility; therefore, it will increase innovation and agility related benefits from CC.

For the above reasons, we expect that higher degree of relational governance of firm's relationships with $\mathrm{CC}$ services providers will lead to more benefits from CC. So, our second research hypothesis is:

H2: The degree of relational governance has a positive effect on CC benefits.

Our third and fourth research hypotheses concern the effects of ICT skills and organization adaptations to the $\mathrm{CC}$ on the benefits obtained from it. In particular, the adaptation of ICT skills, as mentioned in 2.3 [27, 31, 32], should include: a) an enrichment of the technological knowledge and skills of firm's ICT personnel concerning the $\mathrm{CC}$ technologies, the capabilities they provide, their interconnection/ integration with on-premises IS, the monitoring of their quality, etc.; and b) an enrichment of the business knowledge and understanding of the ICT personnel, concerning firm's operations, processes, goals and strategic directions, and in general development of a stronger business orientation of the ICT personnel. The latter is the most important one, as it is going to enable firm's ICT personnel to cooperate with the personnel of the business units, sharing a 'common business language', for: i) the examination, from a business support perspective, of the existing numerous $\mathrm{CC}$ services of interest for the firm; ii) the selection of the most cost-effective and appropriate ones for supporting its operations, business processes and needs in general; iii) the identification of highly valuable integrations that have to be implemented between these $\mathrm{CC}$ services and the existing on-premises IS of the firm; iv) the identification of $\mathrm{CC}$ services that can enable and support beneficial innovations in firm's processes as well as products and services.

At the same time, highly valuable will be the above-mentioned adaptation of firm's ICT personnel skills at the technological level (including enrichment of their technological knowledge and skills on $\mathrm{CC}$ technologies). It is going to enable firm's ICT personnel to examine in-depth from a technological perspective the existing numerous $\mathrm{CC}$ services of interest for the firm (e.g. the specific technologies and platforms they are based on, their security mechanisms, their reliability, as well as their integration capabilities); this will lead to a better selection of CC services to be used by the firm, which not only provide extensive business support, but also are technologically sound and reliable. Furthermore, this technological aspect of firm's ICT skills' adaptation will enable firm's ICT personnel to implement the above identified integrations between the selected CC services and firm's on-premises IS.

Therefore, the above adaptations of firm's ICT skills to the CC paradigm are expected to result in higher efficiency related benefits, as well as innovation support and agility enhancement related ones, from CC. So, our third research hypothesis is: H3: The degree of ICT skills adaptation has a positive effect on CC benefits. 
Beyond the above adaptations of ICT skills, as mentioned in 2.3, the same literature [27, 31, 32] concludes that adaptations are required in the organization of ICT within the firm as well. The most important of them is at a strategic level: development of a CC strategy, linked with firm's overall strategy, concerning the types of $\mathrm{CC}$ services that will be used, the applications they will be used for, the business objectives of $\mathrm{CC}$ use, and also the applications that will remain 'on-premises'. This will enable the firm to advance beyond the uncoordinated and fragmented use of $\mathrm{CC}$ services, towards a more strategic and mature approach to $\mathrm{CC}$ use: to define a complete set of CC services to be used in order to support firm's strategic directions, address its weaknesses, leverage its strengths, seize external opportunities and cope with external threats. Having the above higher level business objectives as a guide for the selection and exploitation of $\mathrm{CC}$ services will lead to higher levels of benefits from $\mathrm{CC}$, concerning the improvement of firm's efficiency as well as agility, the exploitation of strategic new technologies and the support of innovations $[2,15]$. Furthermore, $\mathrm{CC}$ adaptations are required not only at the strategic level, but also at the processes level as well. The development of new relevant processes within the firm for dealing with $\mathrm{CC}$ (e.g. for the quality control of the CC services, for the cooperation with firm's CC providers, as well as for the cooperation between firm's ICT unit and its business units) will lead to more benefits from CC, associated mainly with higher quality of electronic support of firm's activities and business processes, and lower cost of it.

Furthermore, the same literature [27, 31, 32] has concluded that $\mathrm{CC}$ adaptations are required at the level of structure as well: decentralization of CC related decision making, and change of the role of firm's ICT unit. The decentralization of the CC related decisions from the ICT unit to the business units of the firm will increase the involvement of the latter in the exploration of the existing CC services, their assessment, and finally the selection and exploitation of the most cost-effective and suitable ones, in order to support existing operations and business processes, as well as innovations in firm's processes, products and services. The deep business knowledge of the business units can contribute to gaining more benefits from $\mathrm{CC}$ use, associated with higher quality and lower cost electronic support of firm's activities and processes, and also with rapid and low cost electronic support of innovations, as well access to new technologies, through relevant CC services. Furthermore, the change/adaptation of the role of firm's ICT unit, from the internal provision of ICT services towards the central coordination and support of the exploitation of various external CC services, and also their interconnection - integration with firm's on-premises IS, will enable the ICT unit to put more effort on and increase its contribution to the rational and beneficial selection and exploitation of CC services, leading to more efficiency and innovation related benefits from them.

For the above reasons, we expect that higher degree of adaptation of firm's ICT organization to the CC paradigm will lead to higher levels of benefits from CC. So, our fourth research hypothesis is:

H4: The degree of ICT organization adaptation has a positive effect on CC benefits.

\section{Data and Method}

For this study, we have used firm-level data collected from Greek firms through a survey, which has been conducted in cooperation with ICAP S.A. (www.icap.gr), one of the largest business information and consulting companies in Greece. As our starting point, we used the original large sample of Greek firms of ICAP S.A., which to the best of our knowledge is the best and largest source of firm data in Greece. From it we constructed an intermediate smaller sample, with about $50 \%$ of the firms of the initial sample, including 3308 firms, and the same composition by industry and size with the original sample. To these firms of the intermediate sample we sent a questionnaire developed by the authors, which included a large number of questions concerning background information of the firm, ICT usage, and also cloud usage and benefits. For this study, we used part of its questions, which are shown in the Appendix. Finally, we received completed questionnaires from 363 firms (188 small, 131 medium and 41 large ones), having a response rate of about $11 \%$. For this study, we used data from 115 of these firms which are using cloud computing (59 small, 41 medium and, 15 large).

It should be noted that the original sample of ICAP is not representative of the composition of Greek firms by industry. The Greek economy contains thousands of small and very small enterprises in trade, particularly in retail trade, tourism, particularly in catering, and construction. The ICAP sample focuses on the most technologically developed part of the Greek economy: it concentrates on manufacturing $(30.7 \%$ of sample firms) and some modern service industries (such as computer services, business services and transport/communication - $13.7 \%$ of sample firms), still keeping a high percentage of trade and tourism firms $(49.5 \%$ of sample firms); the intermediate 
sample has a similar composition by industry. In the sample, we used in this study (respondent firms using cloud computing) there is a similar representation of manufacturing (26.9\%) and even higher representation of modern service industries (43.1\%). Therefore, our sample structure concentrates on the most technologically developed part of the Greek economy.

In order to test out research hypotheses $\mathrm{H} 1$ to $\mathrm{H} 4$ a linear CC benefits regression model was estimated using these data, with the following specification:

$$
\begin{aligned}
& \text { CC_BENi }=\text { bo }+ \text { b1*C_GOVi }+ \text { b2*R_GOVi }+ \\
& \text { b3*ICT_SKL_ADi }+ \text { b4*ICT_ORG_ADi }+ \\
& \text { b5*D_SIZEi + b6*D_SECTi + ei }
\end{aligned}
$$

The dependent variable is the magnitude of firm's perceived benefits from CC (CC_BEN), measured though a six items scale, shown in the Appendix, which has been developed based on previous literature on CC benefits (section 2.1).

Our model includes four main independent variables, which correspond to the four research hypotheses $\mathrm{H} 1$ to $\mathrm{H} 4$. The first two of them are the degree of contractual and relational governance of firm's relationships with its $\mathrm{CC}$ services providers (C_GOV and R_GOV respectively); the former has been measured through a four items scale, and the latter through a five items scale, both shown in the Appendix, which were developed based on previous empirical research on contractual and relational governance $[8,25,26]$. For each of the above three multi-item scales a principal components analysis was performed; for all three of them the analysis gave one factor (based on the eigenvalues $>1$ criterion), confirming the uni-dimensionality of these scales, which was used as a measure of the corresponding variable. The other two independent variables of our model are the degrees of adaptation of firm's ICT skills and organization to the $\mathrm{CC}$ paradigm (ICT_SKL_AD and ICT_ORG_AD; for measuring them we used a six items scale, shown in the Appendix, which was developed based on previous qualitative research on the adaptations that $\mathrm{CC}$ necessitates in firm's ICT skills and organization [27, 31, 32]. A principal components analysis with Varimax rotation was performed of this scale, which gave two factors (based on the eigenvalues $>1$ criterion). From an examination of the loadings of the items on these two factors it was concluded that the first of them had very high loadings (exceeding 0.9) of the first two items concerning ICT skills adaptations, and much lower loadings of the other four items; therefore, this first factor corresponds to ICT skills adaptation, so it was used as a measure of the ICT_SKL_AD variable. The second factor had high loadings (between 0.75 and 0.85 ) of the last four items, and much lower loadings of the first two items; therefore, this second factor corresponds to ICT organization adaptation, so it was used as a measure of the ICT_ORG_AD variable.

Finally, in our model we have also included two dummy independent variables: one size dummy (D_SIZE), in order to capture the effects of firm size on $\mathrm{CC}$ benefits, taking value 1 for small-sized firms (<50 employees), 2 for medium-sized firms (50 - 249 employees) and 3 for large-sized firms (>250 employees); and another sector dummy (D_SECT), in order to capture the effects of firm sector on CC benefits, taking value 0 for service sectors' firms and 1 for manufacturing or construction sectors' firms.

\section{Results}

In Table 1 we can see the estimated $\mathrm{CC}$ benefits regression model, according to equation 1 of section 4; for each independent variable, the standardized regression coefficients are shown (statistically significant ones at the test levels of $1 \%, 5 \%$ and $10 \%$ are shown with $* * *, * *$ and $*$ respectively).

\begin{tabular}{|c|c|}
\hline $\begin{array}{c}\text { Independent } \\
\text { Variable }\end{array}$ & $\begin{array}{c}\text { Standardized } \\
\text { b Coefficient }\end{array}$ \\
\hline C_GOV & $\mathbf{0 . 1 8 8} *$ \\
\hline R_GOV & $\mathbf{0 . 2 2 4} *$ \\
\hline ICT_SKL_AD & $\mathbf{0 . 3 2 9 * * * *}$ \\
\hline ICT_ORG_AD & $\mathbf{0 . 1 7 8 * *}$ \\
\hline D_SIZE & $\mathbf{- 0 . 2 9 2 * * *}$ \\
\hline D_SECT & -0.083 \\
\hline
\end{tabular}

\section{Table 1. Cloud computing benefits model}

All four main independent variables, the degree of contractual and relational governance of firm's relationships with $\mathrm{CC}$ services providers, as well as the degree of adaptation of firm's ICT skills and organization to the $\mathrm{CC}$ paradigm, have statistically significant positive effects on $\mathrm{CC}$ benefits; so, all four research hypotheses $\mathrm{H} 1$ - $\mathrm{H} 4$ are supported. Also, firm's size dummy has a statistically significant negative effect on $\mathrm{CC}$ benefits, indicating that smaller firms gain more benefits from CC (which is in agreement with the expectations of relevant theoretical literature (e.g. [22, 24, 29]); on the contrary, the effect of the sector dummy is not statistically significant, indicating that service, manufacturing and construction sectors gain similar levels of benefits from CC. 


\section{Discussion - Lessons Learnt}

In the above model of Table 1 we remark that the degree of adaptation of firm's ICT skills has the strongest positive impact on $\mathrm{CC}$ benefits among all four examined factors (standardized coefficient 0.329). This result indicates the importance of the enrichment of the knowledge and skills of firm's ICT personnel, through appropriate training, both at technological level (concerning $\mathrm{CC}$ technologies) and at business level (concerning firm's operations, business processes and strategic directions), for gaining high levels of benefits from CC. This enables the ICT personnel to deal effectively with the technologic aspects of CC usage by the firm, as well with the integration of the external CC services (possibly from different providers) with firm's internal on-premises IS [27]; and also to establish a shared language and understanding, as well as a productive interaction and co-operation, with the personnel of firm's business units, for achieving a highly beneficial exploitation of $\mathrm{CC}$ by the firm. These lead to more benefits from CC. This conclusion indicates the central role and importance of ICT personnel, after appropriate adaptation of their skills to the needs of this new CC paradigm, for its success and for the generation of high business value from it.

From the estimated $\mathrm{CC}$ benefits model we can see also that the second strongest positive effect is the one of the relational governance of firm's relationships with its CC services providers on CC benefits (standardized coefficient 0.224 ). This is in agreement with the conclusions of previous empirical research concerning the positive impact of the relational governance on the outcomes and benefits of ICT outsourcing [16, 17, 25]. This conclusion indicates that though CC services are a simple form of ICT outsourcing, based on the remote provision of highly standardized and minimally customizable ICT services, which are easily accessible in a self-service mode, with minimal interaction with their service provider [22], the development of a relationship with CC service providers continues to be important. This relationship is of critical importance on one hand for solving existing problems and resolving disputes, and on the other hand for gradually increasing the benefits generated by $\mathrm{CC}$ services usage, though open and extensive exchange of information and cooperation between the firm and its $\mathrm{CC}$ services providers, leading to the collaborative generation of ideas for a better exploitation of all the capabilities offered by these CC services. Furthermore, this relationship facilitates the evolution of $\mathrm{CC}$ services used by the firm, in order to meet its evolving needs (e.g. due to changes in its external environment, or innovations in its processes, products and services).

Finally, of similar magnitudes are the positive effects of the contractual governance of firm's relationships with its $\mathrm{CC}$ services providers, and the adaptation of ICT organization within the firm, on $\mathrm{CC}$ benefits (standardized coefficients 0.188 and 0.178 respectively). Therefore, having comprehensive and complex contracts with the $\mathrm{CC}$ service providers, defining the exact services to be provided, their quality levels, as well as sanctions for not achieving them, affects positively the benefits obtained from $\mathrm{CC}$, though to a lower extent than the relational governance. This is also in agreement with the conclusions of previous empirical research concerning the positive impact of the contractual governance on the outcomes and benefits of ICT outsourcing [16, 17, 25].

Also, positive impact on $\mathrm{CC}$ benefits has the adaptation of the organization of ICT in the firm as well, however lower than the one of the adaptation of its ICT skills. The development of a strategic approach to $\mathrm{CC}$ exploitation, as well as specific processes for managing it, the adaptation of the role of firm's ICT unit to the needs of the CC paradigm, and the decentralization of $\mathrm{CC}$ related decisions to some extent from the ICT unit to firm's business units, lead to more benefits from CC. However, such organizational changes are more difficult and slow to implement, reach maturity, and provide significant benefits; so we expect that over time they will deliver more benefits.

\section{Conclusions}

Though extensive empirical research has been conducted concerning the factors that affect the adoption of CC by firms (e.g. see [19]), quite limited empirical research has been conducted concerning the factors affecting the benefit firms obtain from the use of $\mathrm{CC}$ services, and in general the business value from $\mathrm{CC}$.

The study presented in the previous sections of this paper contributes to filling this research gap. It empirically investigates the effects of the contractual and relational governance of firm's relationships with its CC services providers, as well as the adaptations of the skills of firm's ICT personnel, and its internal ICT organization, to this new CC paradigm, on the magnitude of $\mathrm{CC}$ benefits. This study has been based on data collected through a questionnaire from 115 Greek firms using CC services, which have been used for the estimation of a CC benefits regression model. It has been concluded that all the above four 
examined factors impact positively the benefits firms obtain from CC. The effect of the adaptation of the skills of firm's ICT personnel has the strongest effect on CC benefits, followed by the relational governance of the relations with its $\mathrm{CC}$ services providers.

Our study has interesting implications for research and practice. With respect to the former it extends the empirical research that has been conducted concerning the effects of contractual and relational governance on the outcomes and benefits of ICT outsourcing relationships, to the CC paradigm of external sourcing ICT support services. Furthermore, it creates some first evidence concerning the effects of the adaptations of firm's ICT skills and organization to the $\mathrm{CC}$ paradigm on the benefits generated from it. With respect to practice our findings provide some guidance to firms' management for generating higher levels of value from CC. They indicate that the first action firms have to take for this purpose is to provide training to their ICT personnel, both technological (concerning $\mathrm{CC}$ technologies) and business related (concerning firm's operations, business processes and strategic directions). Also, firms have to build good and long relationships with their CC service providers, which promote information exchange, trust, collaborative problem solving, flexibility and mutual adaptation. Furthermore, firms should develop comprehensive contracts with their CC service providers, that provide them sufficient safeguards; and also proceed to adaptations of their internal ICT organization to the CC paradigm: create new relevant strategies and processes, change the role of the ICT unit and increase the involvement of the business units.

This study has two main limitations. First, it has been based on data collected from one country (Greece); so, it is necessary our research questions to be investigated in other national contexts as well. Second, it does not discriminate between different types of CC services, such as IaaS, PaaS and SaaS; so it is necessary to investigate our research questions for specific types of CC services.

\section{References}

[1] Benlian, A. and T. Hess (2011). "Opportunities and Risks of Software-as-a-Service: Findings from a Survey of IT Executives", Decision Support Systems 52(1): 232-246.

[2] Berman, S., L. Kesterson-Townes, A. Marshall, and R. Srivathsa, (2012). "The power of cloud - Driving business model innovation". IBM Institute for Business Value, New York, USA.

[3] Brown, J.R., A.T. Cobb and R.F. Lusch, (2006). "The roles played by interorganizational contracts and justice in marketing channel relationships". Journal of Business Research, 59(2): 166-175.

[4] Brynjolfsson, E., P. Hofmann, and J. Jordan (2010). "Economic and Business Dimensions - Cloud Computing and Electricity: Beyond the utility model", Communications of the ACM, 53(5): 32-34.

[5] Delen, D. and H. Demirkan (2013). "Data, information and analytics as services', Decision Support Systems, 55:1 59-363.

[6] Dyer J. and H. Singh (1998). "The relational view: cooperative strategy and sources of interorganizational competitive advantage". Academy of Management Review 23: $660-67$

[7] Garrison, G., R. L. Wakefield, and S. Kim (2015). "The effects of IT capabilities and delivery model on cloud computing success and firm performance for cloud supported processes and operations", International Journal of Information Management 35(4): 377-393.

[8] Goo, J., R. Kishore, H. R. Rao, and K. Nam (2009). "The Role of Service Level Agreements in Relational Management of Information Technology Outsourcing: An empirical study, MIS Quarterly 33(1): 1-28.

[9] Hoberg, P., J. Wollersheim, and H. Krcmar (2012). "The business perspective on cloud computing - A literature review of research on cloud computing", Proceedings of the American Conference on Information Systems (AMCIS) 2012.

[10] Hoetker, G. and T. Mellewigt (2009). "Choice and performance of governance mechanisms: matching alliance governance to asset type", Strategic Management Journal 30: $1025-1044$.

[11] Huber, T., T. Fischer, J. Dibbern, and Hirschheim, R. (2013). "A process model of complementarity and substitution of contractual and relational governance in IS outsourcing". Journal of Management Information Systems 30(3): 81-114.

[12] Iyer, B. and J. C. Henderson (2010). "Preparing for the Future: Understanding the Seven Capabilities of Cloud Computing", MIS Quarterly Executive 9(2): 117-131.

[13] Iyer, B. and Henderson, J. C. (2012). "Business Value from Clouds: Learning from Users", MIS Quarterly Executive 11(1): 51-60.

[14] Jain, V. K. and S. Kumar (2015). "Big Data Analytic Using Cloud Computing". Proceedings of the Second IEEEE International Conference on Advances in Computing and Communication Engineering

[15] Karpovich, B., L. Kesterson-Townes, and S. Rishi (2017). "Beyond agility - How cloud is driving enterprise 
innovation".IBM Institute for Business Value, New York, USA.

[16] Lacity, M. C., S. Khan, A., Yan, and L.P. Willcocks (2010). "A Review of the IT Outsourcing Empirical Literature and Future Research Directions", Journal of Information technology 25(4)395-433.

[17] Lacity, M., A. Yan, and S. Khan (2017). "Review of 23 Years of Empirical Research on Information Technology Outsourcing Decisions and Outcomes”, Proceedings of the 50th Hawaii International Conference on System Sciences (HICSS) 2017.

[18] Lioliou, E., A. Zimmermann, A., L. Willcocks, and L. Gao (2014). "Formal and Relational Governance in IT Outsourcing: Substitution, Complementarity and the Role of the Psychological Contract", Information Systems Journal 24(6): 503-535.

[19] Loukis, E., S. Arvanitis, and N. Kyriakou (2017). “An Empirical Investigation of the Effects of Firm Characteristics on the Propensity to Adopt Cloud Computing Information Systems and e-Business Management", Information Systems and e-Business Management (in-press).

[20] Lu, Y. and K. Ramamurthy (2011), 'Understanding the Link Between Information Technology Capability and Organizational Agility: An Empirical Examination', Management Information Quarterly 35(4): 931-954.

[21] Malladi, S. and M. Krishnan (2012). "Does Softwareas-a-Service (SaaS) has a role in IT-enabled Innovation? An Empirical Analysis", Proceedings of American Conference on Information Systems (AMCIS) 2012.

[22] Marston, S., Z. Li, S., Brandyopadyay, J., Zhang, and A. Ghalsasi (2011). "Cloud Computing - The Business Perspective”, Decision Support Systems, 51(1): 176-189.

[23] Mellewigt, T., A. Madhok, and A. Weibel (2007). "Trust and formal contracts in inter-organizational relationships: substitutes and complements", Managerial and Decision Economics 28: 833-847.
[24] Müller, S. D., S. R. Holm, and J. Søndergaard (2015). "Benefits of cloud computing: literature review in a maturity model perspective", Communications of the Association for Information Systems 37: 851 - 878.

[25] Oshri, I., J. Kotlarsky, J., and A. Gerbasi (2015). "Strategic innovation through outsourcing: The role of relational and contractual governance", Journal of Strategic Information Systems 24(3): 203-216.

[26] Poppo, L. and T. Zenger (2002). "Do Formal Contracts and Relational Governance Function as Substitutes or Complements?", Strategic Management Journal 23: 707-725.

[27] Ragowsky, A., P. Licker, J. Miller, D. Gefen, and M. Stern (2014). "Do Not Call Me Chief Information Officer, But Chief Integration Officer: A summary of the 2011 Detroit CIO roundtable". Communications of the Association for Information Systems 34(1): 1333-1346.

[28] Schniederjans, D. G., and D. N. Hales, (2016). "Cloud computing and its impact on economic and environmental performance: A transaction cost economics perspective". Decision Support Systems, 86:73-82.

[29] Venters, W. and E. Whitley (2012). “A Critical Review of Cloud Computing: Researching Desires and Reality", Journal of Information Technology 27(3): 179197.

[30] Williamson, O. E. (1989). "Transaction cost economics", In Handbook of Industrial Organization, Vol. 1 (Eds, Schmalensee, R. and Willig, R. D.) Elsevier, Amsterdam, pp. 135-182.

[31] Willcocks, L., W. Venters, and E. A. Whitley (2013). "Cloud sourcing and innovation: slow train coming?", Strategic Outsourcing: An International Journal 6(2): 184 202.

[32] Willcocks L., W. Venters W., and E. A Whitley. (2014). Moving to the Cloud Corporation. Palgrave Millan: UK

\section{$\underline{\text { Appendix }}$}

Answer the following questions in the scale of 1 to 5 , where: $5=$ to a very large extent, $4=$ to a large extent, $3=$ to moderate extent, $2=$ to a small extent $1=$ not at all

To what extent the contracts you have signed with your CC services providers include:

\begin{tabular}{|c|c|}
\hline $\begin{array}{l}\text { The detailed services that have to be offered by the service provider, their quality levels and the } \\
\text { ways/procedures of measurement of them? }\end{array}$ & 12345 \\
\hline Specific sanctions/penalties for the case that these quality levels are not achieved ? & 123345 \\
\hline $\begin{array}{l}\text { Detailed descriptions of forms and ways of communication with the service provider, and } \\
\text { procedures for handling problems and also for disputes' resolution? }\end{array}$ & 12345 \\
\hline $\begin{array}{l}\text { Detailed procedures for covering additional needs of your company in the future, e.g. needs for } \\
\text { higher volumes of services, for new services, for new technologies, etc.? }\end{array}$ & 1 \\
\hline
\end{tabular}


To what extent your relationships with your CC service providers have the following characteristics?

\begin{tabular}{|c|c|}
\hline $\begin{array}{l}\text { There is extensive provision of information by your company to your CC services providers, e.g. } \\
\text { concerning your needs, your problems, your activities and internal business processes, your strategic } \\
\text { goals, etc. }\end{array}$ & 12345 \\
\hline $\begin{array}{l}\text { There is extensive provision of information by your CC services providers to your company, e.g. } \\
\text { concerning the CC services they can offer to you, their technological capabilities, ways of better } \\
\text { exploitation of them by your firm, etc. }\end{array}$ & 12345 \\
\hline $\begin{array}{l}\text { There is a positive attitude from both parties for solving problems and resolving any disputes } \\
\text { between your company and your CC services providers, aiming at mutual benefit and satisfaction of } \\
\text { both parties }\end{array}$ & 12345 \\
\hline $\begin{array}{l}\text { There is positive attitude and flexibility from both parties for responding positively to requests for } \\
\text { changes of the other party (e.g. for making some changes in the services) }\end{array}$ & 12345 \\
\hline $\begin{array}{l}\text { There is a positive attitude of both parties and interest in having a long term business relationship } \\
\text { and co-operation }\end{array}$ & 12345 \\
\hline
\end{tabular}

To what extent the use of CC services by your company has been accompanied/followed by the following complementary actions and internal changes for your adaptation to this new and different model of electronic support of your works and activities?

Enrichment of the knowledge/skills of your IT personnel about CC (e.g. about the technologies of $\mathrm{CC}$, the capabilities it provides, its interconnection/integration with on-premises information systems, the monitoring and management of the contracts and business relationships with $\mathrm{CC}$ providers)

Reinforcement of the knowledge/understanding that your IT staff has about the operations, processes and goals of your company, and the business orientation of your IT staff towards the achievement of business goals and the generation of business value and innovation

Development of new relevant processes in your company (e.g. for the quality control of the CC services, for your cooperation with your CC providers, for the cooperation between your IT unit/group and the other business units that use IT for supporting their works and activities, for meeting their needs for electronic support)

Development of strategy concerning the use of CC services (e.g. what types of CC services will be used, for which groups of applications, and with what objectives, and which groups of applications will remain in 'on-premises' systems)

Decentralization of IT decisions from the IT unit/group to the other business units that use IT for supporting their works and activities. Change of the role of the IT unit/group of your company: from provision of IT services (through applications' development, software packages acquisition, systems administration and support) towards central coordination and support of the selection and use of various CC services, and also interconnection - integration of them with your own on-premises systems

To what extent the use of CC services by your company has provided the following benefits ?

\begin{tabular}{|c|c|}
\hline Reduction of the cost of the electronic support of your activities and business processes & 122345 \\
\hline $\begin{array}{l}\text { Improvement of the quality of the electronic support of your activities and business processes (e.g. } \\
\text { provision of more capabilities/functionalities, higher availability) }\end{array}$ & 12345 \\
\hline Use and exploitation of new technologies without need for additional investments & 12345 \\
\hline $\begin{array}{l}\text { Electronic support and facilitation of the rapid and low cost introduction of products/services } \\
\text { innovations (= new products/services or significantly improved ones) }\end{array}$ & 12345 \\
\hline $\begin{array}{l}\text { Electronic support and facilitation of the rapid and low cost introduction of method/process } \\
\text { innovations (= new methods/processes or significantly improved ones) }\end{array}$ & 12345 \\
\hline $\begin{array}{l}\text { An overall improvement of the 'organizational agility' of your company, defined as its ability to } \\
\text { respond to various changes/challenges in its external environment (e.g. introduction of new } \\
\text { products, services and pricing policies by competitors, changes in market demand for your products } \\
\text { and service, changes in customers' needs/preferences, opportunities for expansion in new markets) }\end{array}$ & 12345 \\
\hline
\end{tabular}

